\title{
DOCUMENTING NEA PAPHOS FOR CONSERVATION AND MANAGEMENT
}

\author{
D. Ace ${ }^{1}$, J. Marrs ${ }^{1}$, M. Santana Quintero ${ }^{1}$, L. Barazzetti ${ }^{2}$, M. Demas ${ }^{3}$, L. Friedman ${ }^{3}$, T. Roby ${ }^{3}$, \\ M. Chamberlain ${ }^{4}$, M. Duong ${ }^{1}$, R. Awad ${ }^{1}$ \\ ${ }^{1}$ Carleton University, Carleton Immersive Media Studio (CIMS) \\ 1125 Colonel by Drive, Ottawa, On, K1S 5B6 Canada \\ darbyace@carleton.ca JamieMarrs@cmail.carleton.ca mario.santana@carleton.ca \\ michelle.duong@carleton.ca reem.awad@carleton.ca \\ 2 Politecnico di Milano, Department of Architecture, Built Environment and Construction Engineering \\ Via Ponzio 31, 20133 Milano, Italy \\ luigi.barazzetti@polimi.it \\ ${ }^{3}$ Getty Conservation Institute, 1200 Getty Drive, Suite 700, Los Angeles, CA 90049-1684, USA \\ MDemas@getty.edu LAfriedman@getty.edu TRoby@getty.edu \\ ${ }^{4}$ Department of Antiquities of Cyprus, 1 Museum Avenue, Nicosia 1097, Cyprus \\ mary24makri@gmail.com
}

Commission II , WG II/8

KEY WORDS: UNESCO World Heritage, Heritage Recording, Digital Documentation, Digital Workflow, Heritage Conservation, Management, Mapping, Archaeological Sites

\begin{abstract}
:
A cornerstone of the management and conservation of archaeological sites is recording their physical characteristics. Documenting and describing the site is an essential step that allows for delineating the components of the site and for collecting and synthesizing information and documentation (Demas, 2012). The information produced by such work assists in the decision-making process for custodians, site managers, public officials, conservators, and other related experts. Rigorous documentation may also serve a broader purpose: over time, it becomes the primary archival and monitoring record. Both scholars and the public use this information and interpret the site, and they can serve as a posterity record in the event of catastrophic or gradual loss of the heritage asset. In May 2018 the Getty Conservation Institute and the Department of Antiquities of Cyprus collaborated with the Carleton Immersive Media Studio in undertaking the documentation of Nea Paphos, a World Heritage site with very important mosaic pavements in the eastern Mediterranean. This contribution outlines the critical components of the documentation project: field study, field measurements, data processing, validation, GIS, and integration of external data. The paper summarizes the digital workflows and procedures used to produce the deliverables, as well as the equipment and technology employed.
\end{abstract}

\section{INTRODUCTION}

Nea Paphos is one of the three UNESCO World Heritage sites in Cyprus, as listed in 1980 under criterions III and VI. As stated by UNESCO (2018), "Paphos, situated in the District of Paphos in western Cyprus, is a serial archaeological property consisting of three components at two sites: the town of Kato Paphos (Site I), and the village of Kouklia (Site II). Kato Paphos includes the remains of ancient Nea Paphos (Aphrodite's Sacred City) and the Kato Paphos necropolis known as Tafoi ton Vasileon ("Tombs of the Kings"), further to the north."

The Roman site of Paphos has been a point of collaboration for the Department of Antiquities of the Republic of Cyprus (DoA) and the Getty Conservation Institute (GCI) since the mid-1980s beginning with the project to conserve the Orpheus mosaic (Stanley-Price, 1991) by detaching it using the rolling technique while training conservators in the region. An assessment of the mosaic followed this work in 2005. In 2014 the DoA and the GCI cooperated in delivering a training course on conservation and management of archaeological sites as part of the GCI's MOSAIKON initiative.

(http://www.getty.edu/conservation/our_projects/education/mos aikon).

As a result of the subsequent meetings between the GCI and the DoA and the successful collaboration to record the conditions of the Orpheus and the Amazon \& Heracles mosaics in 2017, the GCI and the DoA are pursuing a sustainable future for the World Heritage Site of Nea Paphos and its Necropolis, known as the
Tombs of the Kings, by preparing a Conservation and Management Master Plan (CMMP) for the site.

To provide the groundwork for the CMMP, Carleton Immersive Media Studio (CIMS) was commissioned to produce a digital record of the as found conditions of the site. The project has a dual purpose: to provide the GCI and the DoA of Cyprus with the capacity to use the heritage information system to guide conservation objectives, as well as to provide a means to improve visitor understanding and experience of the site .

The approach for digital workflows to document the site developed (Figure 1) by CIMS had the following aims:

- $\quad$ accurate acquisition of the current state of conservation of Nea Paphos with the use of appropriate and suitable technology;

- $\quad$ plan and implement recording and mapping activities aimed at the production of metric records to facilitate the conservation planning of the mosaics at the site and the broader conservation and management of Nea Paphos;

- $\quad$ design and produce a Geographic Information System for the site; and,

- provide local staff with a meaningful learning experience in the use of GIS, as well as the specific recording and mapping technologies used in the project.

The paper will illustrate the techniques and methods used for the project, which is currently in progress. 


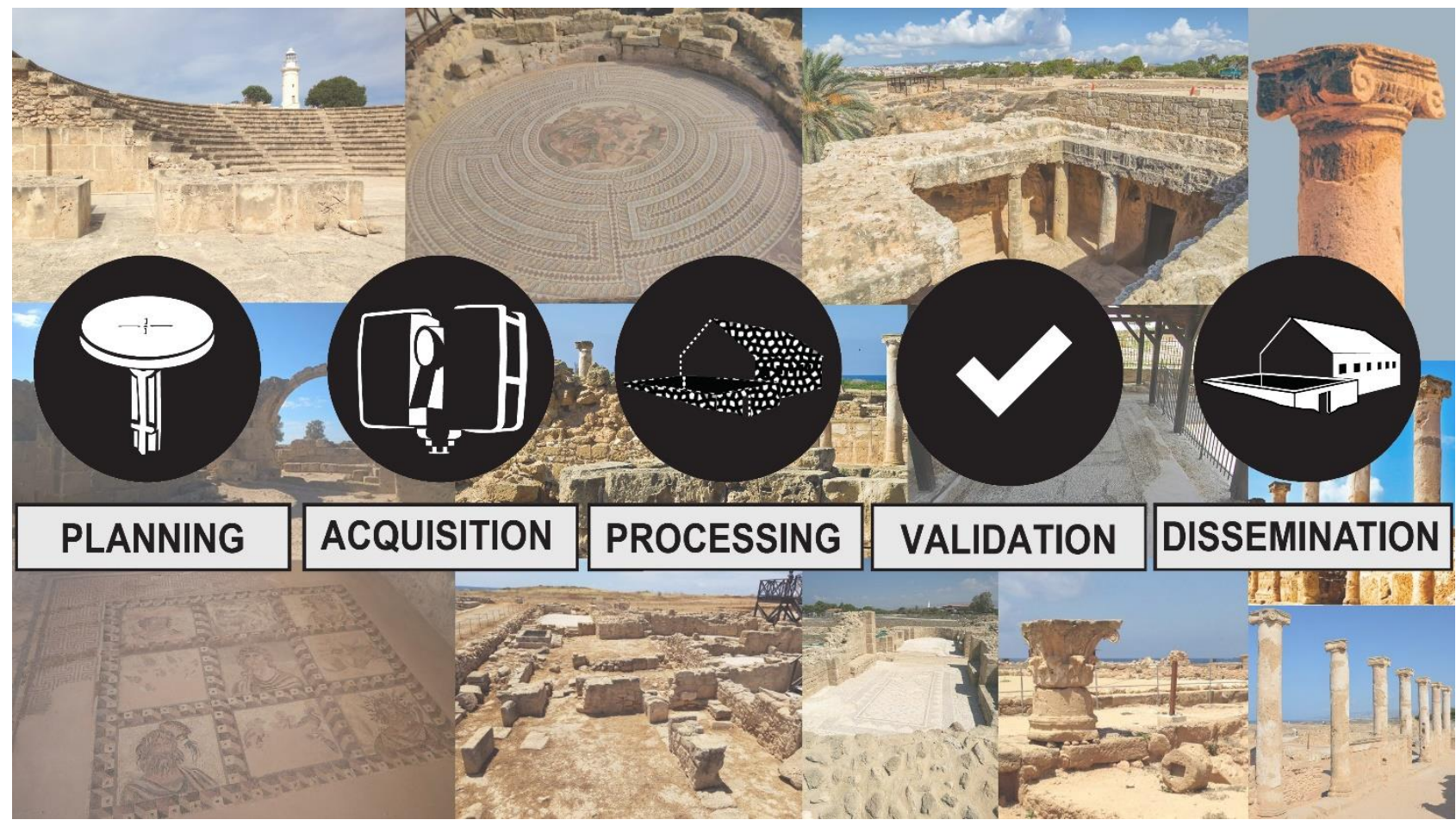

Figure 1. The schematic workflow for digital documentation with some images of the archeological site of Nea Paphos.

\section{THE DIGITAL DOCUMENTATION WORKFLOW}

\subsection{Overview}

Preparation for the project began with two days on site. This site visit allowed assessment of the working conditions, the scope of the project, and it also facilitated the planning of the timeline, team, and methodology to achieve the proposed scope of work. The planning phase involved defining the scope and deliverables of the recording and training activities, as well as logistical arrangements of equipment and transportation.

The fieldwork, or acquisition phase, involved the implementation of the developed strategy based on multiple tools, focusing primarily on the archaeological site and the Basilica of Chrysopolitissa area. The broad-scale recording also covered the Tombs of the Kings and Fabrika areas, to be further documented in future phases of the project.

The geomatics team established a reliable control network across the entire site using a variety of survey tools. The survey network allowed for the final deliverables to be georeferenced and incorporated into the GIS. This team included a senior geodetic specialist who worked with the Cypriot Land Survey Department to produce the network.

The documentation team performed the terrestrial photogrammetric and 3D scanning survey of the site features, collected digital information, and processed the deliverables. A team from Geoimaging Ltd., a local Cypriot company, was responsible for the global aerial photography of the site.

Documentation techniques included the use of an Unmanned Aerial System (UAS) to capture aerial photography for photogrammetric use, as well as a 3D scanner to fill in areas not visible from the aerial view, such as underground, under trees and inside buildings. High-resolution photographs of the exposed mosaics were captured using a handheld DSLR camera for terrestrial photogrammetry.

The quality and accuracy of the outputs were validated throughout the entirety of the project beginning with preprocessing and various checks throughout the acquisition phase. Validation through the processing phase was done through numerous emails, on-site field checks and conference calls between CIMS, the GCI, and the DoA to verify decisions and discuss complications.

The project outputs were disseminated through numerous forms of digital deliverables and protocols in addition to personnel training and capacity building workshops.

The various phases of the project workflow are described in further detail in the following sub-sections.

\subsection{Photogrammetric documentation using an Unmanned Aerial System (UAS)}

Given the extensive area of the site, a UAS was used to capture aerial images for production of photogrammetric mapping and numerous deliverables (e.g., ortho-corrected images, digital terrain models (DTM), etc.). For this task, Geoimaging Ltd. was sub-contracted and they conducted flights at the height of $50 \mathrm{~m}$. A series of eighteen flight paths were set up to capture the entirety of the archaeological site, the areas covering Fabrika, the Basilica of Chrysopolitissa, the Frankish Baths, and the Tombs of the Kings. As previously indicated, the UAS followed a series of parallel paths at the height of $50 \mathrm{~m}$ above sea level, capturing a single image every $5 \mathrm{~m}$ to $10 \mathrm{~m}$ (see Figure 2). The drone used was a DJI Phantom 4 Pro, equipped with a 1" CMOS camera providing 20 million pixels resolution: $5472 \times 3648$ pixels. 
For areas of greater importance, such as areas with exposed ruins, a secondary flight using the same UAS device at $20 \mathrm{~m}$ was used to capture the area in higher detail which is appropriate for tracing stone-by-stone level of detail. The flight plans were organized using the Pix4D Capture application that allows automatic programming of the flight height, velocity of the drone, and overlap according to the desired Ground Sampling Distance (GSD) or level of detail. Figure 3 shows the difference in resolution between photos taken at $20 \mathrm{~m}$ versus $50 \mathrm{~m}$.

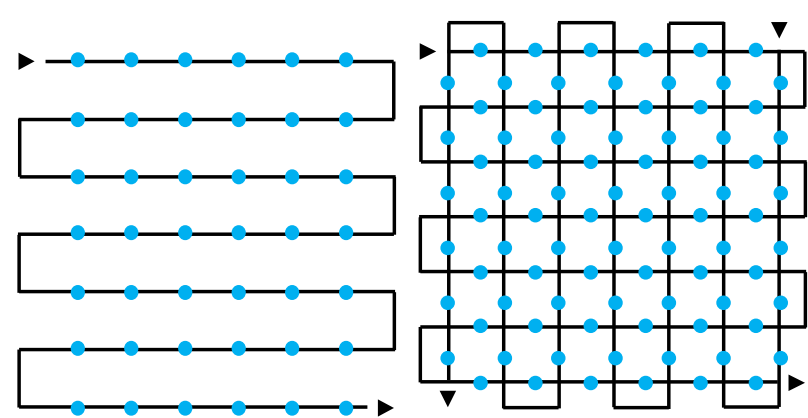

Figure 2. Grid pattern flight path $-50 \mathrm{~m}$ (left), and Double grid pattern flight path $-20 \mathrm{~m}$ (right).
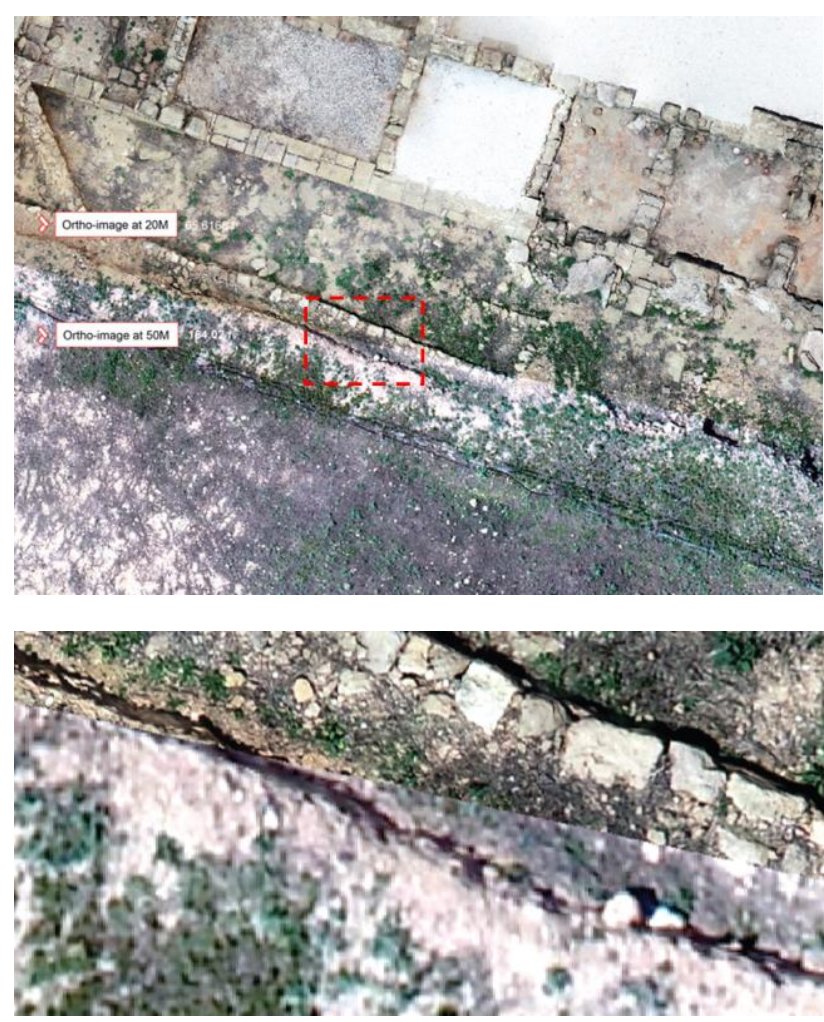

Figure 3. Difference in level of detail between photos taken at different heights (20 m - GSD $6 \mathrm{~mm}$, and $50 \mathrm{~m}$ - GSD $15 \mathrm{~mm}$ ).

Ground control points (GCPs) were measured across the entire archaeological site and into the urban area using satellite-based positioning, i.e., Global Navigation Satellite System (GNSS) through Real Time Kinematic positioning (RTK). The GCPs were captured by both the Land Survey Department of Cyprus for the total station set-up locations as well as by Geoimaging Limited as control points for the aerial photography. The GCPs were tied together by CIMS and used to establish a control network using a Reflectorless Electronic Distance Measurement (REDM) total station (Leica Geosystems TS11). The control network allowed for additional total station set-up locations to be chosen and numerous natural points and targets to be measured providing georeferencing data for the photogrammetry and 3D scanning outputs.

Total station measurements (distances and angles) were adjusted via Least Squares using the free network method. The software used was Leica Geo Office v8. The computed coordinates were georeferenced on the GNSS points with a 4-parameter transformation (scale, rotation, and two translation parameters). Some GNSS checkpoints (i.e., not directly used for the estimation of the transformation) confirmed residual errors better than 2.5 $\mathrm{cm}$. To summarize, the achieved error was comparable with the expected precision of GNSS points and confirms the high metric accuracy of the measurements. The total station was used to support the photogrammetric and 3D scanning records by providing measured control points to georeference the generated models. The computed control point coordinates were then used in the different photogrammetric projects obtaining errors comparable with the ground sampling distance of the images. Such results also confirm the good metric accuracy of the control point dataset.

In total, forty-three control points were marked and documented for future use. Each GCP was recorded with context photos and a witness sheet was created to provide point identification, coordinates, and a written visual description for locating that point in the future.

For the $50 \mathrm{~m}$ photogrammetry, over 7,000 aerial photographs of the site were captured and provided by Geoimaging: 5,450 over the archaeological site and Chrysopolitissa area and 1,650 over the Tombs of the Kings. Due to this high quantity of photographs, the project team separated the archaeological site into three tiles to reduce computational cost and processing time.

Bentley's ContextCapture was used for the processing of the 50 $\mathrm{m}$ photogrammetry. This software was chosen from experience as it has proven to produce good quality results for large areas in past projects. The GCPs were used as control points in the software to georeference the model and aid with the accuracy of the topography. The resulting orthophoto from the $50 \mathrm{~m}$ photogrammetry has a resolution of $15 \mathrm{~mm}$ (GSD).

The project team processed the $20 \mathrm{~m}$ photogrammetry in much the same way by separating the site into critical areas based on the various UAS flights. In addition to using GCPs, control points were also taken from the $50 \mathrm{~m}$ photogrammetry to supplement areas where there was inadequate control, as well as to serve as check points to ensure the accuracy of alignment. The resulting orthophoto from the $20 \mathrm{~m}$ photogrammetry has a resolution of 6 $\mathrm{mm}$. Figure 4 shows some images of the products created in the area around the Odeon.

ContextCapture exports the final orthophoto in regular tiles; the quantity depends on the RAM capabilities of the computer. The different tiles were then merged using ArcGIS Pro to obtain georeferenced ortho-photos.

Additional considerations on DSM, DTM, contour lines or other cartographic products are illustrated and discussed in the next sections. 


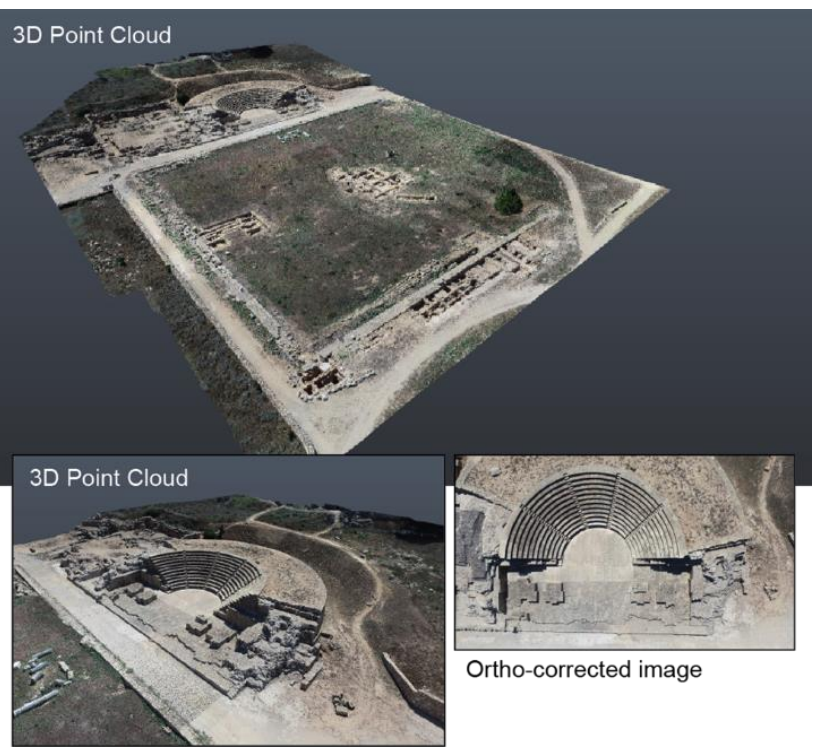

Figure 4. Some details of the deliverables for the $20 \mathrm{~m}$ photogrammetric project in the area around the Odeon.

\subsection{Terrestrial photogrammetry}

Terrestrial photogrammetry was used to generate high-resolution ortho-photos of exposed mosaics on the site, focusing primarily on those in the north and south Residential Areas within the main archaeological site. The workflow in Figure 5 outlines the process of converting photogrammetric images from the RAW files, as captured with the DSLR camera and mirrorless camera, to high-resolution orthographic images for integration in the GIS system.

A sequence of overlapping images was captured for each mosaic, ensuring that all the areas of the surface were recorded in at least three images. The photographs were taken with a full frame DSLR photographic camera Nikon D800 (Nikon, 2016) with a $50 \mathrm{~mm}$ or a $20 \mathrm{~mm}$ mounted lens that achieved a resolution of 36.3 megapixels using the Nikon Raw format. Raw photography allows for a broader range of adjustments using processing software (Peterson, 2009), such as Adobe Photoshop, as used in this project.

To optimize the quality of the photogrammetry outcome, the photos required consistently even exposure. To achieve this, even lighting conditions were required. Given the lighting conditions within the contemporary shelters, i.e., multiple light sources, variable lighting conditions, bright areas, and shadows, the best results were achieved by taking photos just before sunset so that the lighting could be controlled using flashes. A sequence of overlapping photographs was taken using the CIPA $3 \times 3$ rules (CIPA, 2018) to cover the entire surface of the mosaics. A color card (Xrite ColorPassport) was used to control the white balance of the photographs; the exposure remained constant throughout the photography (McCarty, 2014).

For exposed, unsheltered mosaics the overlapping photographs were taken a few hours before sunset or during overcast skies using the slowest shutter speed possible and the smallest aperture to ensure higher quality images. The same settings were used for exposed, sheltered mosaics, although in some cases external illumination was achieved with the strategic placement of a lighting kit. The kit consisted of four flashes equipped with diffusers and wireless transmitters mounted on light stands or placed on the floors. The legs of the flash tripods were protected with plastic to prevent any damage to the mosaics.

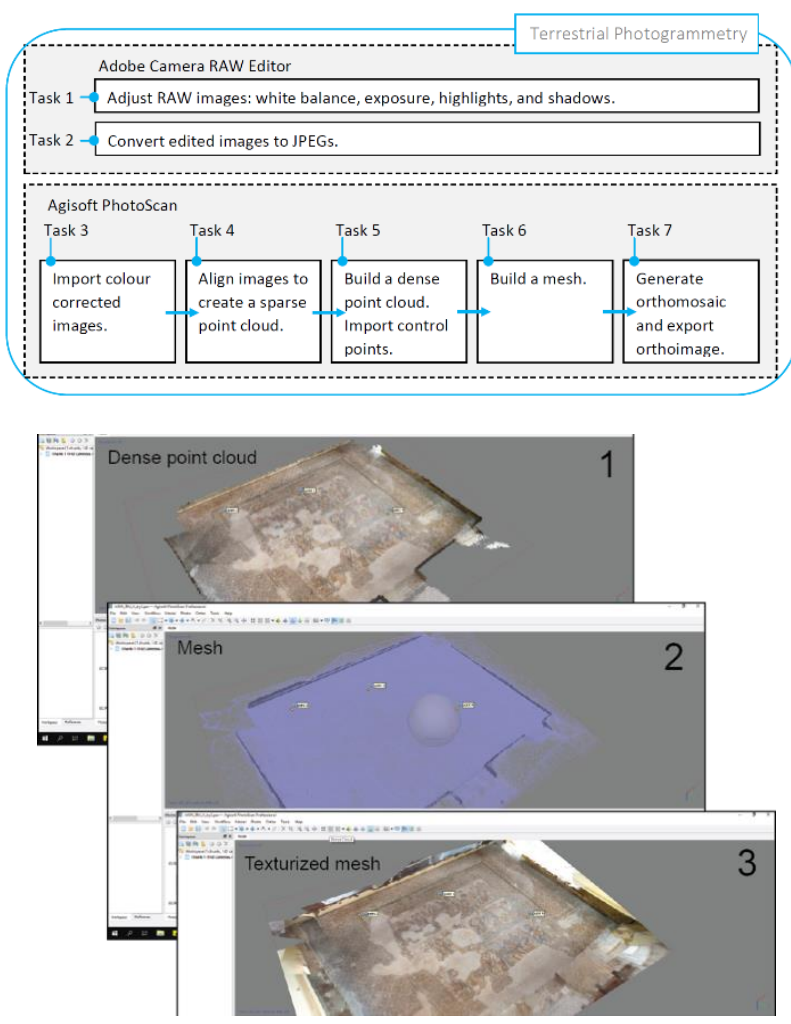

Figure 5. Processing workflow for the mosaics using terrestrial photogrammetry.

The photos were referenced to points taken from the 3D scan data and total station data using natural targets from the decorated surfaces captured in the same photos, while preventing any damage to the integrity of the surfaces.

\subsection{Terrestrial 3D scanning}

For the purpose of this project 3D scanning was used to supplement the data captured through aerial photography, including in areas under high-density vegetation and/or within sheltered archaeological remains.

A highly portable, high-resolution laser scanner was used: Faro Focus 3D CAM2 HDR X130. This device, used with a lightweight fiberglass tripod, allowed for data capture in small areas with limited access, which provided more accurate and complete results.

Prior to the commencement of scanning, numerous chessboard targets and six spheres were strategically placed to provide identifiable connections between scans, which then allowed for the point cloud to be registered quickly and accurately. The target locations must be chosen in a way that they are visible from at least two viewpoints. Regarding the target configuration, it is important to mention that the targets should be located such that they are distributed in different directions and not collinear. Several sets of point cloud data can be merged together from separate scanning positions if adequate overlap between scans is ensured and controlled survey points are established. 
For referencing to control points, it is necessary to clearly see at least two targets whose coordinates have been measured with the total station. These targets are the control points used to orient and reference the resulting point cloud. In well-lit areas, $360^{\circ}$ photographs were taken; these photos were used to assign color to the points, which improved the readability of the point cloud for tracing purposes. This workflow is summarized in Figure 6.
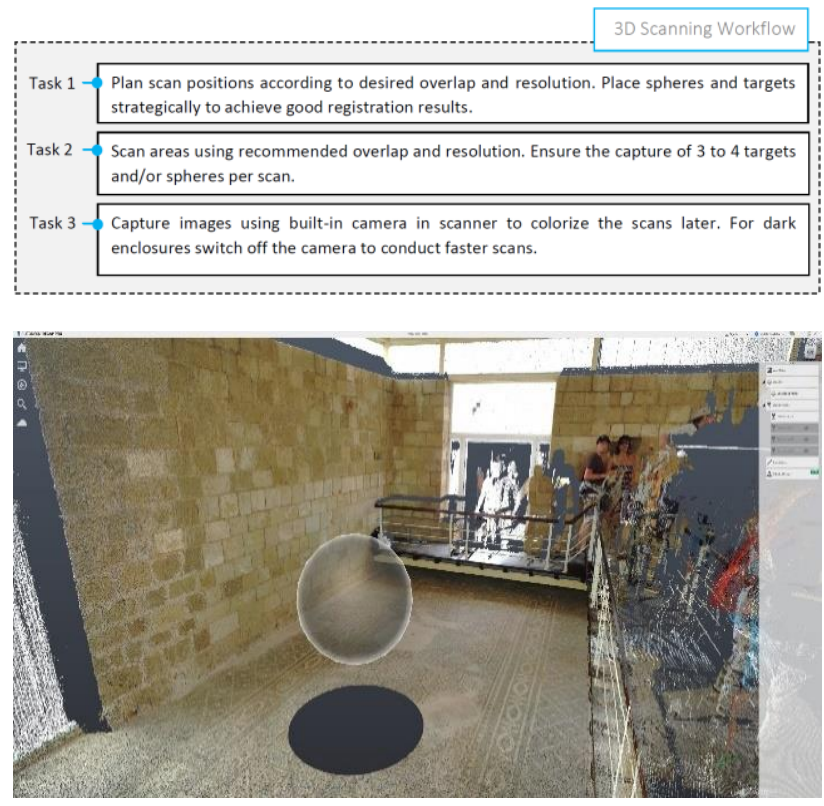

Figure 6. 3D Scanning workflow and point cloud from mosaics at the Aion shelter.

As mentioned, the point clouds acquired with the laser scanner must be registered in a common reference system to become useful for the production of measured drawings. The evaluation of registration quality plays a fundamental role in the delivery of accurate technical drawings.

Targets became reference points to establish the final reference system of each project so that the final point clouds were provided in the Cypriot reference system CGRS93 / Cyprus Local Transverse Mercator, (EPSG:6312). The software used for data processing was Faro Scene version 2018.

After extraction of the target centers, correspondences can be established between individual points from different viewpoints. Based on this information transformation parameters among the laser stations can be computed and finally applied to the corresponding point clouds yielding a registered dataset.

An alternative approach used in this project relies on redundantly captured regions of point clouds and forms the family of surfacebased registration algorithms. This was the case for scans without a good distribution of targets. A substantial advantage of this strategy over target-based registration is the actual use of the redundant information present in the overlapping region of two or more point clouds. The surface-based registration algorithm used in this work is named iteratively closest point algorithm (ICP), where point-to-point correspondences are established. The method is also known as "cloud-to-cloud registration" in Faro Scene.

\section{PRODUCTION OF CAD DRAWINGS}

As Howard (2006) suggests, the recording and description of a monument are quite separate from interpretation; the former is intended as an accurate (within the limits set for the survey) statement of the current form of the archaeological structures, while the latter may change in the light of developments in the wider study of sites.

For the preparation of line drawings (Figure 7), an accurate base record was produced from the photogrammetry and 3D scanning data; this limited the degree of interpolation needed between the onsite conditions and readable measured drawings that reflect the needs of the GCI and DoA for this project.
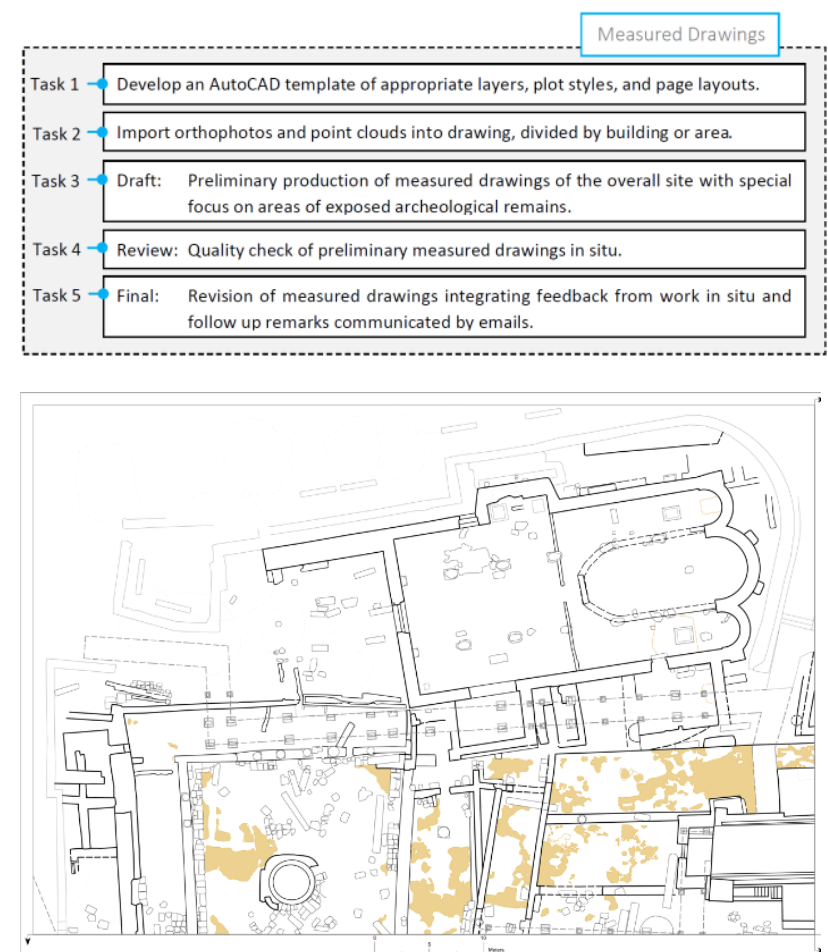

Figure 7. Workflow for production of measured drawings and resulting line drawing of a part of the site, showing preserved remains of mosaic pavements.

First, a template and drawing standards were developed to allow for consistency and efficiency throughout the drawing process. A layout template, layer names, and a plot style have been developed for this project. A thoroughly developed set of layers and conventions were used to trace the visible elements of the site. The naming of a layer was done by (site)-(type of feature)(description of feature). All features were divided into one of four types: ancient (A), drawing (D), modern (M), or site (S). The final part of the layer name is a shortened description of the features on that layer.

Preliminary measured drawings were produced in AutoCAD Map 3D 2018. The primary source of data drawings were $20 \mathrm{~m}$, georeferenced, aerial orthophotos by area. Areas not visible from above were filled in using point cloud data as captured by the $3 \mathrm{D}$ scanner. The GCI and DoA staff and consultants worked together with the CIMS team in reviewing the measured drawings in situ. Extensive annotated drawings were produced to correct and adjust the preliminary set. The measured drawings were adjusted based on the aforementioned site notes as well as back and forth review with the GCI. Adjustments were made to improve the completeness, accuracy, and readability of the plans. 


\section{GEOGRAPHIC INFORMATION SYSTEM}

Geographic Information Systems (GIS) have become an essential tool in the research, management, and conservation of archaeological sites. A GIS combines the collection of geographic data and other sources of information and can be used to generate/simulate scenarios pertinent to the site. The final GIS data was generated with different GIS software, considering the future use and users of the data. The choice was to use traditional cartographic formats in a way that users with commercial GIS software (e.g., ESRI ArcGis Pro or ArcMap), free or open source GIS software (e.g., GRASS, QGis, etc.), or remote sensing packages (e.g., ERDAS, ENVI, PCI Geomatics, etc.) could read, retrieve and manage the different files without the need of preliminary conversions.

The various data was produced in the Cyprus reference system starting from the GNSS coordinates measured in RTK. Raster and vector files have a reference system associated with different files so that automatic georeferencing is possible after importing specific files.

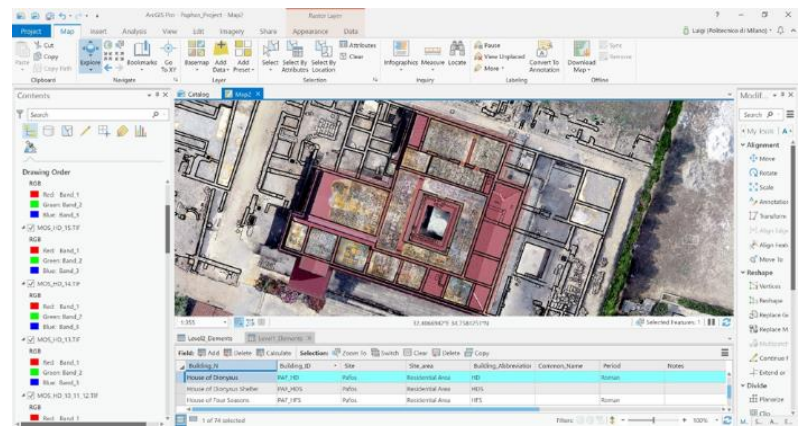

Figure 8. Example of some files opened using ArcGIS Pro. (There is no reference to figure 8 in the text.)

Data processing was carried out using various software to overcome the lack of commercial packages for the entire production workflow. In addition, image pyramids and tiles were created to speed up importing the large ortho-photos produced from high-resolution images.

Digital Surface Models (DSMs) were created from the images acquired with the drone (Figure 9). The software used to create such data was ContextCapture, which allows the direct interpolation of the point cloud to generate a raster model in the GeoTIFF format. The different tiles produced by ContextCapture were merged into single files corresponding to the areas of interest using ArcGIS Pro. Two DSMs from the $50 \mathrm{~m}$ drone flights were created for the archaeological site and the Tombs of the Kings, respectively. Spatial resolution was set to $5 \mathrm{~cm}$. The drone flights with an elevation above ground at $20 \mathrm{~m}$ allowed the DSMs to be produced with a resolution of $1.5 \mathrm{~cm}$.

Digital Terrain Models (DTMs) were created from the DSMs with a resolution of $5 \mathrm{~cm}$, i.e., those in the archaeological site and the Tombs of the Kings. Elements that do not belong to the ground were isolated and removed from the DSM. Such elements include vegetation, buildings, cars, and people, among others. The occlusions were then filled using interpolation algorithms. Data filtering has been carried out preserving the archeological areas, which are therefore mapped in both DSMs and DTMs. Small vegetation, such as bushes, was filtered with smoothing algorithms able to identify and flatten local anomalies.
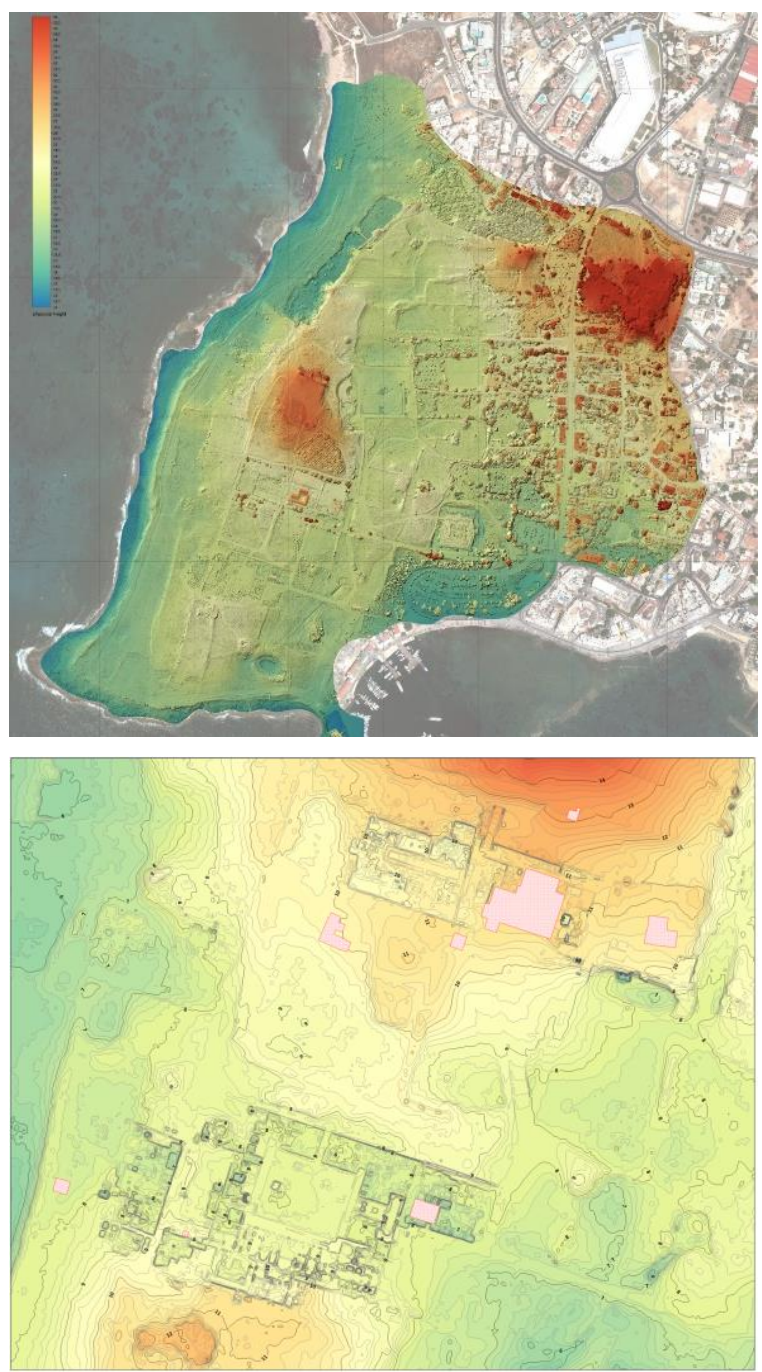

Figure 9. Example of the DSM of the archaeological site (top) and a detail of contour lines derived from the DTM (bottom).

Contour lines were generated from both DSMs and DTMs (Figure 9). Contour lines from the DTMs are available for the archaeological site, the Fabrika area and the Tombs of the Kings. The provided elevation value is the ellipsoidal height in the Cypriot reference system as well as the orthometric height. The interval for contours from the DTM is $0.5 \mathrm{~m}$. A smoothing lowpass filter has been applied to the original DTMs to generate smoother contour lines. In fact, the direct generation of contour lines from a DTM with a very high geometric resolution $(5 \mathrm{~cm})$ tends to produce fragmented contour lines with an unrealistic shape. The preliminary use of a low-pass filter produces contour lines which are more similar to those traditionally produced in cartographic applications. Contour lines from the DSMs were instead generated only for the $20 \mathrm{~m}$ flights using the corresponding $1.5 \mathrm{~cm}$ grids.

The measured drawings divided by building or area were also integrated in the GIS (Figure 10). Mosaics and other pavements were classified as exposed or reburied. The GIS includes many other elements, such as rooms, buildings, walkways, shelters, etc. 

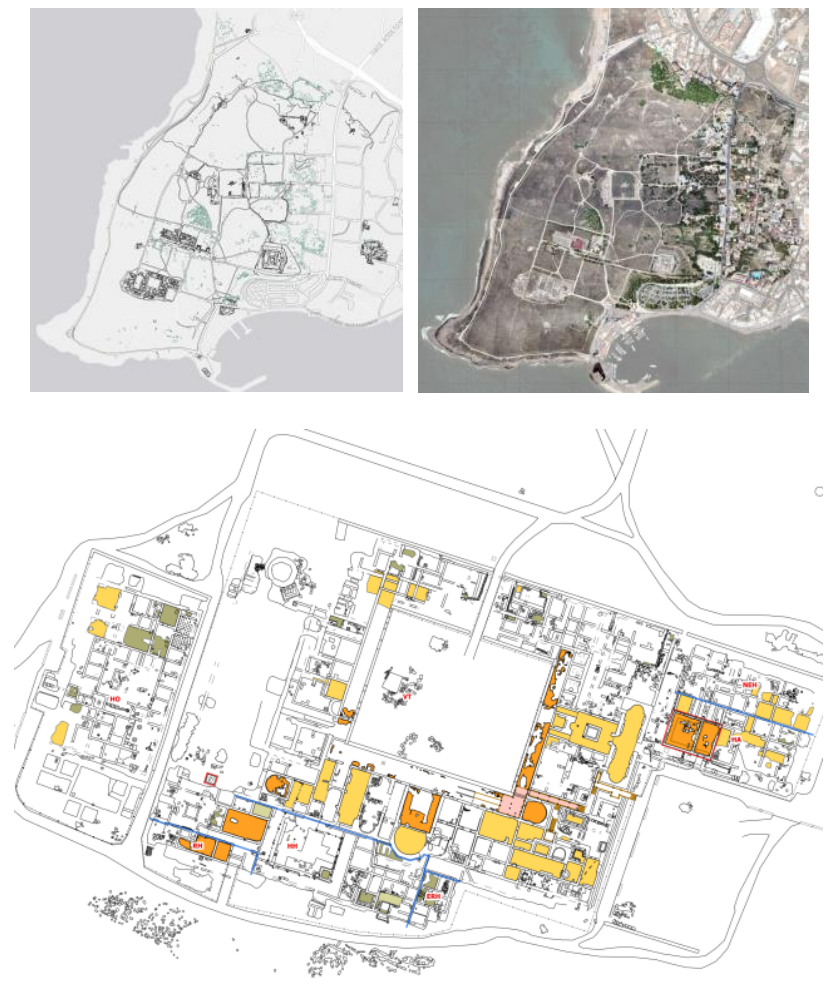

Figure 10. Example of line drawings and an ortho-photo of the archaeological site.

A relational database has been setup to allow for rapid information retrieval as well as the opportunity to add additional data. The solution is a geo-database, which means that a geometric representation of specific objects is added to the GIS project. The visual-geometric representation allows users to access the database without working on the database tables. The structure of the database is based on a multi-level approach that ranges from the wider "objects" to the different elements that belong to the previous level using a sequential strategy.

The previous products are only a subset of the produced deliverables. The GIS also integrated data provided by the DoA including aerial images produced in different years and the official UNESCO boundaries, available as a shapefile. In addition, CIMS provided the acquisition and production of new data: control points as shapefiles with additional links to the witness pages for select points; files related to water drainage and stream computation were made available as raster files (slope) and vector shapefiles (the computed streams); panoramic images (see the next section) were linked to the GIS through point shapefiles.

\section{VIDEO AND VR}

As indicated by Renfrew and Bahn (2016), "aerial photography is crucial to [archeological site] recording and interpretation and to monitoring changes in them through time." With the portability and ease of new UASs, capturing aerial views has become very fast and achievable.

A preliminary video was produced combining footage from select locations around the site allowing the viewer to get a general perspective of the site from the air. Furthermore, aerial photographs were taken of the site. These photographs were taken at a height of $25 \mathrm{~m}$ and oblique to the areas (Figure 11).

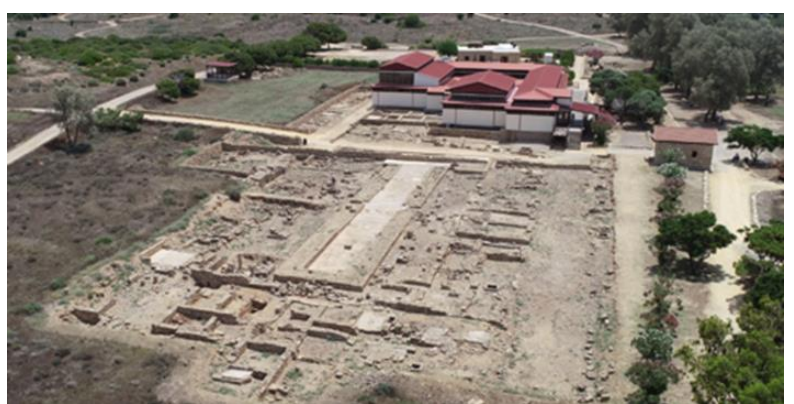

Figure 11. Aerial view of the north Residential Area.

A virtual tour was also created using several panoramic images. The project team captured spherical panoramic images of select locations around the archaeological site to give users a better contextual and experiential understanding of the site. For this project, the team used a Nikon D300 DSLR camera equipped with a $10 \mathrm{~mm}$ Nikkor fisheye lens (12.3 megapixel DX format CMOS sensor) that permitted a Field of View of around $180^{\circ}$ which was diagonally mounted on a Nodal Ninja panoramic adapter on a Manfrotto tripod. The Nodal Ninja is an attachment which allows the photographer to take a series of overlapping images at regular intervals of $60^{\circ}$, for complete coverage of $360^{\circ}$ of the captured scene. For this purpose, several images were taken at each location: 12 at different horizontal angles to improve the stitching when photographing in open skies, 6 at $45^{\circ}$ up, and 2 down (masking was used to partially remove the tripod). This method allowed for adequate overlap between photos for processing.

All photos were taken using the Nikon Raw format with slow shutter speed and suitable aperture to achieve the sharpest images possible. The sets of raw panoramic images were adjusted using Adobe Photoshop. As with terrestrial photogrammetry, a photo containing the color card was used for correcting the white balance and subsequently JPEG images were produced. The different images were then correlated by a set of homographic transformations, which were estimated from corresponding points automatically detected in adjacent images. The different images were then resampled and stitched using an equirectangular projection. The software used was PTGui. In addition, in order to complete the panoramic tour some images were taken using a Ricoh Theta S panoramic camera. This device is equipped with two $180^{\circ}$ lenses allowing the automatic production of a $360^{\circ}$ still image in a single shot; however, the resolution does not match that which is achieved with the Nodal Ninja and Nikon camera. The different panoramas were imported and linked in a virtual environment where the user can navigate the virtual scene using a geographic viewer (Figure 12).

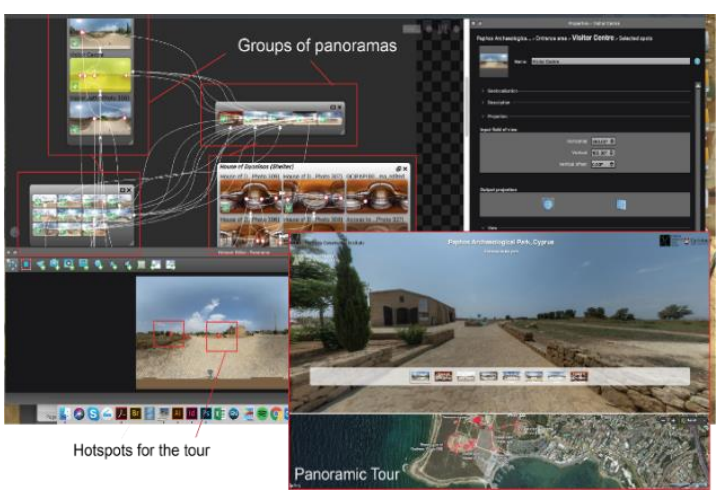

Figure 12. The generation of the virtual tour. 


\section{CONCLUSIONS AND FURTHER RESEARCH}

The collaborative approach developed for the recording of the asfound condition of the Nea Paphos archaeological site for conservation and management planning has been challenging yet rewarding. It met several goals in the production of an accurate heritage record of a large, complex site by utilizing sophisticated, yet affordable tools, and has enhanced the capacity of the Department of Antiquities in Cyprus to continue the work through training in the use of GIS and recording techniques.

Beyond the technical challenges of this work, there were other difficulties encountered in recording an ancient site such as Nea Paphos that has been undergoing active excavation for many decades. Most of the excavated structures were constructed of rubble masonry, and during the intervening centuries of use, reuse, and disuse, they have suffered collapse, removal of stones for use elsewhere, and exposure through excavation for many decades, leading in some cases to further decay. Ongoing excavations result in continual changes to the topography and exposed remains, changing the data from one recording campaign to the next. Additionally, much of the site is yet to be excavated and consists of irregular terrain and extensive vegetation cover. The vegetation forms habitats for birds and includes many wildflowers that are a significant natural feature in the landscape and therefore its removal and the methods used are subject to limitations. Due to these factors, the capture of the archaeological structures by drone and subsequent processing is made difficult and requires extensive field checking after initial processing and the input of archaeologists to interpret the remains.

The Nea Paphos project team collaborated in developing an effective digital workflow for recording the exposed mosaic pavements (sheltered and unsheltered), but several limitations were identified. A particular challenge was achieving consistent lighting conditions to capture quality photography of mosaics under protective shelters. Photographic capture of unsheltered mosaics is hampered by their current condition, which in many cases has made their decoration less visible; the practice of wetting mosaics to enhance colors for photography is rarely used today because of its potentially deleterious effect. For this reason, the team is currently developing an approach to help overcome these limitations using non-invasive techniques; this will be trialed in Phase 2 of the project.

The second phase of mapping which began with site work in June 2019 involves recording extensive underground spaces in the Fabrika and Tombs of the Kings areas to complete the heritage record of the first phase. The work of capturing a complicated underground topography over a vast area offers further challenges, but the framework and experience developed in Phase 1 provide a solid basis for addressing them.

\section{ACKNOWLEDGMENT}

The Carleton Immersive Media Studio (CIMS) project team would like to acknowledge the Getty Conservation Institute and the Department of Antiquities of Cyprus for the opportunity to collaborate on this outstanding project.

Also, we would like to acknowledge the support of Stephen Fai, Laurie Smith, Danustan Alphonza and the rest of the CIMS staff for the continued assistance throughout the project.

\section{REFERENCES}

CIPA.icomos.org., 2018. The 3X3 Rules. [online] http://cipa.icomos.org/wp-

content/uploads/2017/02/CIPA_3x3_rules_20131018.pdf [Accessed 2 Feb. 2019].

Demas, M., 2012. Planning for conservation and management of archaeological sites: A values-based approach. In Sullivan, S. and Mackay, R. (2012). Archaeological sites. Los Angeles: Getty Conservation Institute.

Grussenmeyer, P., et al., 2016. Basics of range based modelling techniques in cultural heritage recording. In Stylianidis, E. \& Remondino, F. (eds.) 3D Recording, Documentation and Management of Cultural Heritage. Dunbeath: Whittles.

Howard, P., \& Taylor \& Francis Group., 2006. Archaeological surveying and mapping: Recording and depicting the landscape. New York: Routledge.

Hartley, R., Zisserman, A., 2003. Multiple view geometry in computer vision. Cambridge university press, Cambridge

Kraus, K., 2008. Photogrammetry: Geometry from Images and Laser Scans. Second edition .Walter de Gruyter. 459 pages.

Letellier, R. Schmid, W. LeBlanc, F., 2007. Guiding Principles Recording, Documentation, and Information Management for the Conservation of Heritage Places [online]. Available at: http://www.getty.edu/conservation/publications_resources/pdf_ publications/recordim.html [Accessed 19 Dec. 2018].

Luhmann, T., Robson, S., Kyle, S. and Harley, I., 2006. Close Range Photogrammetry: Principles, Techniques And Applications. John Wiley \& Sons. 510 pages.

McCarthy, J. , 2014. Multi-image photogrammetry as a practical tool for cultural heritage survey and community engagement. Journal of Archaeological Science 43.

Peterson, B., 2009. Understanding photography. New York: Amphoto

Renfrew, C., Bahn, P.G., 2016. Archaeology: Theories, methods, and practice (Seventh revised \& updated.). London: Thames and Hudson.Theolt.com. (2018). Photography for PhoToPlan3D: the $3 \times 3$ rules $\gg$ TheoLt. [online] Available at: http://www.theolt.com/web/photography-for-photoplan3d-the3x3-rules/ [Accessed 19 Dec. 2018].

Stanley-Price, N., 1991. The Conservation of the Orpheus Mosaic at Paphos, Cyprus. Marina del Rey, CA: Getty Conservation Institute.

Styliandis, E., Patias, P., Quintero Santana, M., 2009. CIPA Heritage Documentation. Best practices and applications. In: The ISPRS International Archives of Photogrammetry, Remote Sensing and Spatial Information Sciences, Athens, Greece, Vol. XXXVIII

UNESCO, 2018. Paphos. [online] Whc.unesco.org. Available at: https://whc.unesco.org/en/list/79 [Accessed 19 Dec. 2018]. 